\title{
AS VIAGENS FILOSÓFICAS DE JOÃO DA SILVA FEIJÓ (1760-1824) NO CEARÁ
}

\author{
Philosophical voyages of João da Silva Feijó \\ (1760-1824) in Ceará
}

Clarete Paranhos da Silva*

\begin{abstract}
RESUMO
João da Silva Feijó (1724-1860) foi um entre os diversos naturalistas que trabalharam a serviço da Coroa portuguesa no levantamento dos recursos naturais da então colônia portuguesa da América, na transição do século XVIII para o século XIX. Feijó, que foi sócio correspondente da Academia Real das Ciências de Lisboa, empreendeu uma viagem filosófica pelas Ilhas de Cabo Verde, onde teria permanecido de 1783 a 1797. Depois de retornar dessa viagem, permaneceu por algum tempo em Portugal, preparando-se para sua vinda para a Capitania do Ceará, onde chegaria em 1799. Uma das obras científicas mais relevantes do século XVIII português, as Viagens filosóficas foram também importantes no processo de institucionalização das ciências naturais no Brasil. Este trabalho irá se debruçar sobre as de João de Silva Feijó, no Ceará, dando ênfase a aspectos ligados aos campos da mineração, da Mineralogia e da Geologia daquele período.
\end{abstract}

Palavras-chave: história das ciências; viagens filosóficas; BrasilColônia.

\footnotetext{
ABSTRACT

João da Silva Feijó (1760-1824) was among some naturalists who were sponsored by the Portuguese crown in order to make an inventory of the natural resources in colonial Brazil in the transition from the $18^{\text {th }}$ to the $19^{\text {th }}$ centuries. Feijó - correspondent member of the Royal Academy of Sciences of Lisbon - carried out a philosophical voyage to the

${ }^{*}$ FIPEP/SP
} 
Cape Verde Island where he probably stayed from 1783 to 1797 . After returning from this voyage, he spent some time in Portugal preparing for his philosophical voyage to Ceará, where he arrived in 1799. One of the greatest scientific enterprises in the $18^{\text {th }}$ century in Portugal and the kingdom, the Philosophical voyages are also considered as being very relevant in the process of institutionalization of natural sciences in Brazil. The present paper should be dedicated to Feijó's work in Ceará, emphasizing its aspects connected to mining, mineralogy and geology at that time.

Key words: history of sciences; philosophical voyages; Colonial Brazil.

As Viagens filosóficas, considerada uma das obras científicas mais importantes do século XVIII português, constitui-se em marco dentro do processo de emergência e institucionalização das ciências naturais no Império luso, particularmente no Brasil. Este trabalho se dedicará a alguns aspectos das investigações de João da Silva Feijó, no Ceará - com ênfase nas de cunho mineralógico -, considerando-as como parte de um amplo conjunto de práticas científicas realizadas no espaço colonial que permitiram a institucionalização das ciências naturais também na América portuguesa.

\section{O naturalista João da Silva Feijó}

Nascido na Capitania do Rio de Janeiro, em 1760, e falecido em março de 1824, na mesma capitania, seus biógrafos se dividem quanto ao fato de Feijó ter ou não cursado a Universidade de Coimbra. ${ }^{1}$ A partir das leituras de suas Memórias, não resta dúvida que o naturalista Feijó inclui-se entre os discípulos

1 Para os que afirmam que sim, embora não precisem exatamente suas fontes, veja-se: SIMOM, W. J. Scientific expeditions in the Portuguese overseas territories (1783-1808) and the role of Lisbon in the intellectual-scientific community of the late eighteenth century. Lisboa: Inst. de Investigação Científica Tropical, 1983; CARREIRA, António. Apresentação e comentários. Ensaio e memórias econômicas sobre as Ilhas de Cabo Verde (século XVIII), por João da Silva Feijó. Lisboa: Inst. Caboverdiano do Livro, 1986; GUEDES, Maria Estela; ARRUDA, Luís M. Feijó: naturalista brasileiro em Cabo Verde século XVIII. In: As Ilhas e o Brasil. Portugal/Madeira: Centro de Estudos de História do Atlântico; Secretaria Regional de Turismo e Cultura, 2000, p. 509-523. Silva Nobre sugere que Feijó teria cursado a Academia Militar de Lisboa, por não ter encontrado seu nome nas relações de alunos formados no período em Coimbra. Cf. SILVA NOBRE, Geraldo da. João da Silva Feijó: um naturalista no Ceará. Instituto Histórico do Ceará. Fortaleza: Grecel, 1978. 
de Domingos Vandelli ${ }^{2}$, qualquer que tenha sido a instituição em que fez seus estudos. Evidência disso pode ser constatada nas palavras do professor da Universidade de Coimbra quando escreve, na sua Descrição e análise química do cobre virgem, ou nativo descoberto no ano de 1782 na Capitania da Bahia, que em seus ensaios foi auxiliado por "Alexandre Rodrigues Ferreira, Galvão, Silva e Feijó (os quais trabalhavam antes em várias experiências de tinturaria [...] desse Real Museu)". ${ }^{3}$

Em companhia de Alexandre Rodrigues Ferreira (1756-1815), Feijó realizou, em fins de 1778, uma diligência filosófica na região de mineração de carvão de Buarcos, em Coimbra. ${ }^{4}$ A viagem teve como resultado uma descrição completa da referida mina acompanhada por desenhos, conforme esclarece carta de Vandelli, depositada no Arquivo Histórico Ultramarino. ${ }^{5}$

Feijó, que foi sócio correspondente da Academia Real das Ciências de Lisboa, empreendeu uma viagem filosófica pelas Ilhas de Cabo Verde, onde teria permanecido de 1783 a 1797. Durante esse período, manteve correspondência sistemática com Júlio Mattiazi - responsável pelo Jardim Botânico de Coimbra, e também da Ajuda - com Vandelli e outras autoridades portuguesas. Desde sua estadia em Cabo Verde até sua chegada ao Ceará, elaborou diversos artigos, posteriormente publicados pela Academia

2 O italiano Domingos Vandelli (1730-1815) foi o primeiro lente de Química e História Natural da Universidade de Coimbra após as reformas pombalinas. Exerceu suas atividades naquela instituição entre os anos de 1772 e 1791. Foi um dos mais vigorosos impulsionadores da criação da Academia Real das Ciências de Lisboa (1779). Vandelli transitou por alguns dos espaços de investigação mais importantes criados durante o processo reformista iniciado pelo ministro de Dom José I, Marquês de Pombal (1699-1782), e continuado por seus sucessores. Durante seu trabalho como professor e investigador em Coimbra, Vandelli e seus alunos utilizavam o Laboratório Químico, o Gabinete de História Natural e o Jardim Botânico. Ao mesmo tempo Vandelli participava ativamente dos trabalhos da Academia Real das Ciências de Lisboa, como diretor da classe das ciências da observação, bem como do Museu da Ajuda.

3 IEB/USP, Coleção Lamego, 70, A, 8.

4 SIMOM, W. J. Scientific expeditions in the Portuguese overseas territories (1783-1808) and the role of Lisbon in the intellectual-scientific community of the late eighteenth century. Lisboa: CEHCA; Inst. de Investigação Científica Tropical, 1983.

5 Maço 26, Reino, 4/1/1779: “A exata descrição da Mina de Carvão com as figuras está acabada, e o Alexandre entre poucos dias partirá para restituir-se à Corte, e apresentá-la a Vossa Excelência.” 
Real das Ciências de Lisboa e outros periódicos. ${ }^{6}$

Depois de retornar de Cabo Verde, permaneceu por algum tempo em Lisboa, onde escreveu um Discurso político sobre as minas de ouro do Brasil $^{7}$, sendo também encarregado de fazer experiências com o salitre da Ribeira do Alcântara, deixando sobre esse trabalho um documento intitulado Estado presente das experiências do salitre na Ribeira do Alcântara em $1 .^{\circ}$ de março de $1798^{8}$. A meu ver, essas experiências com o salitre preparavam Feijó para a sua vinda ao Ceará, onde, como veremos adiante, seus primeiros esforços se concentraram nesse material mineral.

\section{Trajetória de Feijó no Ceará e seus exames sobre salitre}

Em 1. ${ }^{\circ}$ de fevereiro de 1799, Feijó recebe o cargo de SargentoMor das Milícias 9 , chegando ao Ceará em outubro de $1799 .{ }^{10} \mathrm{O}$ objetivo de Feijó na capitania seria o de cumprir aquilo que lhe fora designado em provisão de 25 de fevereiro de 1799, assinada por D. Maria I: estudar todas as potencialidades naturais da região. ${ }^{11}$

6 Além de seus trabalhos sobre a Capitania do Ceará, Feijó deixou inúmeros outros documentos escritos, que englobam desde sua estadia em Cabo Verde até sua chegada ao Brasil, nomeadamente ao Ceará: Estado presente das experiências do salitre na Ribeira do Alcântara, em 1. ${ }^{\circ}$ de março de 1798. Biblioteca Nacional de Lisboa, reservados, cód. 610 (F.R. 762). Memória sobre a fábrica real de anil da Ilha de Santo Antão. Publicada nas Memórias Econômicas da ARCL, tomo 1, 1789, p. 407-421. Memória sobre a urzella de Cabo Verde. Memórias Econômicas da ARCL, tomo 5, 1815, p. 145-154. Ensaio político sobre as ilhas de Cabo Verde para servir de plano à história filosófica das mesmas. Publicado no Patriota, n. 5, nov. 1813. Memória sobre a última erupção vulcânica do Pico da Ilha do Fogo, sucedida em 14 de Janeiro do ano de 1785, observada e escrita, etc.. Publicada no Patriota, tomo 3, n. 5, 1814, p. 23 a 32 . Ensaio econômico sobre as Ilhas de Cabo Verde, publicado pela Academia Real das Ciências de Lisboa, em 1815. Itinerário Filosófico que contem a relação das ilhas de Cabo Verde, disposta pelo método epistolar. Dirigidas ao Ilustríssimo e Excelentíssimo Senhor Martinho de Mello e Castro, pelo naturalista régio das mesmas ilhas João da Silva Feijó, 1783. Biblioteca Nacional do Rio de Janeiro, manuscritos, cód. 12984. Discurso politico sobre as minas do Brasil. Manuscrito no Museu Paulista, Coleção José Bonifácio, D-79.

7 Manuscrito no Museu Paulista, Coleção José Bonifácio, D-79.

8 Biblioteca Nacional de Lisboa, Reservados, códice 610 (F.R. 762).

9 AHU, caixa 13, doc. 727, Queluz, 1/2/1799.

10 AHU, caixa 13, doc. 749, Fortaleza, 1/1/1800.

11 Livro de Registro da Vedoria Geral da Capitania do Ceará. Fls. 9v e 10v. 
Desde pelo menos o ano de 1735 se tem notícias de que o governo português buscava inventariar possíveis recursos minerais na região que abrange o atual estado do Ceará. ${ }^{12}$ As investigações do naturalista Feijó na capitania indicam uma retomada dessas iniciativas anteriores. A partir da chegada do naturalista, inicia-se a troca de uma intensa correspondência ${ }^{13}$ que envolveu as autoridades da Capitania do Ceará, as autoridades de Lisboa e Feijó. Essa documentação não somente evidencia o esforço oficial no fomento às investigações em História Natural na região, como também nos revela que o naturalista não realizou seu trabalho de maneira solitária e isolada.

Tanto Feijó como outros naturalistas que realizaram investigações em História Natural na América portuguesa trocaram intensa correspondência, tanto com autoridades de Lisboa como com as autoridades locais. Havia, portanto, no período aqui tratado, uma conexão entre os atores que participaram do processo de realizar uma "História Natural" no espaço colonial do Brasil, mediada pelas autoridades da colônia, da Coroa e pelas instituições de investigações portuguesas coordenadas por Domingos Vandelli. Regra geral eram as autoridades metropolitanas que enviavam cartas e avisos para os governantes locais solicitando o trabalho de naturalistas. Esses, por sua vez, comunicavam os resultados de seus trabalhos

12 AHU, caixa 3, doc. 164, Ceará, 14/1/1735.

13 Por exemplo, ofício de Feijó a Dom Rodrigo falando de suas viagens a Baturité, Canindé e Serrote do Rosário para processar análises do solo (AHU, caixa 13, doc. 763, Ceará, 1/7/1800); ofício do governador Bernardo Manuel de Vasconcelos para Dom Rodrigo relatando as despesas feitas por Feijó na região de Tatajuba (AHU, caixa 13, doc. 771, Fortaleza, 1/4/1800); ofício do governador Bernardo Manuel a Dom Rodrigo sobre ordem para o exame dos minerais, árvores e plantas da Capitania do Ceará. O governador avisa que "hei de fazer aplicar os conhecimentos filosóficos e químicos do Bacharel Naturalista empregado nesses assuntos" (AHU, caixa 14, doc. 815, Fortaleza, 31/12/1800); ofício de Feijó ao secretário de negócios da Marinha e Ultramar João Rodrigues de Sá e Melo sobre as minas de salitre de Tatajuba (AHU, caixa 15, doc. 876, Ceará, 15/11/1801); ofício do governador Bernardo Manuel de Vasconcelos ao Visconde de Anadia (João Rodrigues de Sá e Melo) sobre o salitre necessário para a confecção de pólvora (AHU, caixa 16, doc. 904, Fortaleza, 31/3/1802); ofício do governador Bernardo Manuel de Vasconcelos para o Visconde de Anadia sobre a abertura de uma estrada do Baturité até Tatajuba (AHU, caixa 17, doc. 944, Fortaleza, 30/9/1802); ofício de Bernardo Manuel ao Visconde de Anadia remetendo caixotes de salitre (AHU, caixa 15, doc. 879, Fortaleza, 31/12/1801); ofício de João de Almeida Melo e Castro ao Visconde de Anadia sobre remessa de 13 caixotes de salitre enviados da Capitania do Ceará que deveriam ser remetidos para a refinaria de Alcântara, em Lisboa (AHU, caixa 16, doc. 911, Sete Rios, 12/4/1802); ofício dos governadores interinos ao Visconde de Anadia sobre incentivo à extração de salitre (AHU, caixa 17, doc. 989, Fortaleza, 14/5/1803); ofício do governador João Carlos Augusto Oeynhausen ao visconde de Anadia sobre remessa de sementes e outros produtos naturais da Capitania do Ceará pelo naturalista João da Silva Feijó (AHU, caixa 18, doc. 1036, Fortaleza, 18/5/1804); ofício de João da Silva Feijó ao visconde de Anadia remetendo dois caixotes com sementes de plantas recolhidas na Serra de Ibiapaba, um para o Jardim Botânico da Ajuda e outro para o de Sua Majestade prussiana (AHU, caixa 19, doc. 1109, Ceará, 3/2/1806). 
aos governadores e, muitas vezes, diretamente às autoridades portuguesas. Suas Memórias, desenhos e amostras eram enviadas para Lisboa e levadas para as diversas instituições do Reino. Em íntima relação com o Estado, essas instituições atuavam no treinamento e na organização para as "viagens filosóficas", produziam "Instruções de viagem" e sistematizavam o conhecimento produzido, muitas vezes difundindo-os através de publicações, como foi o caso das Memórias e das Breves instruções $^{14}$, publicadas pela Academia Real das Ciências de Lisboa.

A documentação levantada e analisada nos mostra que o trabalho de Feijó abarcou todos os objetos da História Natural da época. Ao mesmo tempo, ao desvelar o cotidiano de seu trabalho, não só coloca em evidência algumas de suas dificuldades, como também que tipo de material instrumental - sejam instrumentos ou livros - ou humanos, era por ele solicitado ou utilizado em suas "fadigas literárias".

Em carta de 13 de dezembro de 1800, Feijó escreve ao Visconde de Anadia informando sobre as minas de salitre encontradas e queixando-se das condições de trabalho. Pede que suas necessidades sejam atendidas, para o bom progresso de seus serviços. Entre outras coisas, solicita a última edição do Sistema geral de Lineu, uma Flora guianense, a Enciclopédia metódica botânica, imprensa (prensa) e papel para dissecar plantas, instrumentos de medição para calcular a latitude onde se encontram as minas, um laboratório portátil para os ensaios químicos dos minerais e um "desenhador". Observa que essas "providências que não sendo fora de costume, deram-se a todos os meus colegas"15. Tal "queixa" de Feijó é mais uma evidência que demonstra a movimentação de diversos naturalistas na América portuguesa, cujos trabalhos eram concomitantes ao dele.

Em 1803, Feijó escreve novamente ao Visconde de Anadia justificando-se pelo fato de ter remetido salitre misturado com algum "muriato de soda". Diz que a falta de aparelhos próprios e de soluções químicas apropriadas para seus exames químicos "são a causa de nunca poder me livrar de um erro involuntário". Pede que seja socorrido com "um pequeno, porém sortido laboratório químico portátil para estas e outras averiguações e exames químicos". No mesmo documento, afirma ter entregado ao governador 2.752 libras de nitrato de potassa e também um caixote de sementes

14 BREVES instruções aos correspondentes da Academia das Ciências de Lisboa sobre as remessas dos produtos e notícias pertencentes à história da natureza para formar um museu nacional. Lisboa: Régia Oficina Tipográfica, 1781.

15 AHU, caixa 14, doc. 811, Ceará, 13/12/1800. 
de plantas para ser enviado ao Real Jardim Botânico. Diz que remeteu também amostras de petrificações de peixe e anfíbios da serra dos Cariris Novos e amostras de minerais como prata e cobre. ${ }^{16}$

As primeiras investigações do naturalista, relacionadas ao salitre, dão-se em uma localidade denominada Tatajuba. A dedicação de Feijó e de outros naturalistas às investigações sobre o salitre, essencial para a produção de explosivos, explica-se pelo fato de que, nesse período, as pesquisas sobre esse bem mineral se intensificaram devido à conjuntura internacional, que exigia investimentos na defesa das nações e de suas colônias. No contexto do que alguns historiadores chamam de crise do Antigo Sistema Colonial, as ameaças constantes de invasões ou de espionagem eram uma realidade sempre presente. Diante desse quadro, uma intensa correspondência trocada entre as autoridades coloniais e da Coroa recomendava explicitamente a busca de depósitos de salitre e remetia livros sobre o assunto. E, ao mesmo tempo em que naturalistas espalhados por todo o Império tratavam de cumprir as ordens explícitas da Coroa, no Reino homens de ciência realizavam experimentos na tentativa de obter pólvora de melhor qualidade. ${ }^{17}$ Em julho de 1804, na administração do governador João Carlos

16 AHU, caixa 17, doc. 971, Fortaleza, 20/2/1803.

17 AHU: caixa 13, doc. 748 e 757 ; caixa 14, doc. 780,811 e 819 ; caixa 15 , doc. 866 e 876; caixa 16, doc. 904; caixa 17, doc 987 e 989 . Todos os documentos referem-se a exames de salitre na Capitania do Ceará em finais do século XVIII e início do século XIX realizados pelo naturalista João da Silva Feijó. O mineralogista José Vieira Couto também pesquisou salitre em Minas Gerais em 1803, escrevendo uma Memória que foi publicada em livro pela Imprensa Régia, em 1809 (BNRJ, obras raras, 37, 2, 9). Nitreiras são exploradas na Bahia, por José de Sá Bittencourt Aciolli (1755-1828). E o padre Joaquim José Pereira escreveu, em 1801, uma Memória sobre o sal de Glauber Salitre Quina e mais produções nativas. Essa Memória deriva de suas observações nas capitanias do Piauí e do Maranhão. É acompanhada de um diário de suas observações e contém um quadro dos produtos naturais e sua respectiva localização (IEB, catálogo 2376, cód. 78). Em aviso de 31/3/1797, enviado ao vice-rei do Brasil por Sua Alteza Real, é recomendado o descobrimento de terras próprias para a extração do salitre. Junto ao aviso, são remetidos impressos com instruções de como se fabricar salitre (Providências expedidas sobre o Brasil, 1796-1800, BNRJ, manuscritos, 6, 3, 9). Em 21/6/1797, um outro aviso recomenda ao vice-rei e a todos os governadores das capitanias para facilitar o descobrimento do salitre e de terras próprias para a sua extração. Junto com o aviso é mandado um livro impresso com o Método de conhecer as terras onde se produz e existe o mesmo salitre (BNRJ, manuscritos, 6, 3, 9). E Vandelli, nas suas Várias observações de Química e História Natural, relata, entre outras coisas, suas experiências para "acrescentar a força à pólvora". Ele diz: "purificado o nitro com o modo ultimamente descoberto, para livrá-lo totalmente do sal marinho o fiz dissolver com água emprenhada de gás inflamável, que obtive na decomposição da água em gás inflamável, fazendo evaporar ou destilar a água em maior quantidade do que é necessário para a sua total decomposição: com essa solução salina irrorei a mistura do enxofre, e carvão, e continuei a manipulação. Desse modo obtive uma pólvora, que supera de muito em força todas as qualidades de pólvoras até agora conhecidas" (Coleção Memórias da Academia Real das Ciências de Lisboa, tomo I - desde 1780 até 1788. Lisboa: Tipografia da Academia, 1797). 
Augusto Oyenhausen, o laboratório de Tatajuba é transferido para a região de Pindoba, na serra de Ibiapaba. O próprio Feijó explicou que a transferência se devia ao empobrecimento e deterioração das minas de salitre da região de Tatajuba. ${ }^{18}$ Segundo o naturalista, a produção em Tatajuba estava "empobrecida e deteriorada". Ao examinar as nitreiras em Pindoba e arredores, Feijó chega à conclusão de que a transferência seria um bom negócio. ${ }^{19}$ O laboratório de Tatajuba foi extinto em 1804 pela decadência em que se achavam as minas de salitre da região, conforme dito pelo próprio Feijó. O de Pindoba, em 1805, porque, segundo as autoridades locais, não estava compensando as despesas. ${ }^{20}$

Desde a morte do governador Bernardo Manoel de Vasconcelos, Feijó enfrentava problemas com os governadores interinos, que não davam o suporte necessário e até mesmo se opunham aos seus trabalhos, como o próprio naturalista deixa claro em algumas de suas correspondências com a Coroa.

Em ofício datado de 15 de janeiro de 1803 , enviado para a Coroa, Feijó, ao mesmo tempo em que agradece a "aprovação de minhas diligências filosóficas", fala da morte do governador que sempre o animara em "suas fadigas literárias" como um "sensível golpe". Reclama que o governo interino era apático com relação à questão do salitre e que, apesar de suas repetidas representações para obter os meios para continuar os trabalhos em Tatajuba, só recebia respostas vagas que "nem faziam suspender, nem continuar" os trabalhos. ${ }^{21}$ Em resposta à posição do governo interino, que afirmava que a produção não estava compensando as excessivas despesas, Feijó acha seu dever "por na presença de Vossa Excelência uma análise individual e possivelmente circunstanciada da mesma despesa". Ainda comunica o envio de amostras minerais, menciona experimentos com certas espécies de carvão para feitura de pólvora e remete uma amostra da pólvora que

18 Pode-se ter uma visão sobre o trabalho de Feijó nos laboratórios de Tatajuba e de Pindoba pela leitura de diversos ofícios do naturalista datados de 1803 e 1804 (Arquivo Histórico da Casa da Moeda de Lisboa. Laboratório de Química, 1801-1826. Arq. 1 - maço 718).

19 Arquivo Histórico da Casa da Moeda de Lisboa. Laboratório de Química, 1801-1826. Arq. 1 - maço 718 .

20 Ofício da Junta da Fazenda ao Vice-Rei do Brasil (Luiz de Vasconcelos e Souza) datado em 2 de junho de 1807. Publicado em NOGUEIRA, Paulino. O naturalista João da Silva Feijó. Revista trimensal do Instituto do Ceará, ano 2, tomo 2, 1888, p. 247-276.

maço 718 .

21 Arquivo Histórico da Casa da Moeda. Laboratório de Química, 1810-1826. Arq. 1 - 
"fiz em pequeno". Aproveita para reclamar de problemas de saúde pelos "23 anos continuados no serviço do mesmo Augusto Senhor, tanto em Cabo Verde como por estes áridos sertões", solicitando, em seguida, um "emprego menos laborioso", visto que sua presença não era mais necessária. Pois, para "a conduta futura destas oficinas, caso se tornem a por em exercício este aproveitamento, aqui estão sujeitos hábeis que de antemão para isso tenho instruído". ${ }^{22}$ Juntamente com o ofício, Feijó envia uma "relação das despesas que se hão feito em várias diligências filosóficas de que estou encarregado nesta Capitania do Ceará desde o mês de outubro de 1799, até dezembro de 1802"23. Apesar das campanhas do naturalista em favor da manutenção dos trabalhos dos "Reais" laboratórios de salitre, prevaleceu a posição do governo da capitania, para o qual as despesas não compensavam os gastos e os mesmos foram fechados.

Mas o trabalho de Feijó não cessou. O naturalista continuou suas investigações tanto mineralógicas quanto botânicas e zoológicas. Em suas variadas incumbências, classificou plantas e por diversas vezes enviou caixotes ao Real Jardim Botânico da Ajuda e para a instituição congênere da Prússia, em Berlim. Por exemplo, em ofício dirigido ao Visconde de Anadia remetendo frutos do Ceará, Feijó afirma que, em cumprimento das ordens dos governadores interinos, "tenho aprontado as poucas sementes que na forma das instruções recebidas me foram possíveis recolher". Anexa ao ofício, segue uma "relação de sementes das plantas agrestes do Ceará que se envia para Sua Alteza Real pela Secretaria de Estado dos Negócios e Ultramar para se dirigirem à corte de Berlim". ${ }^{24}$ Em ofício de 15 de janeiro de 1803, o naturalista faz referência a um pequeno viveiro "das mais particulares árvores e arbustos do país no quintal do Real laboratório de refinação do salitre". Segundo Feijó, seria melhor se as plantas remetidas ao

22 O atestado médico datado de 12 de março de 1803, assinado pelo cirurgião-mor da Capitania, Manoel Joaquim Garcia, e enviado para a Coroa, menciona, entre outras coisas, "uma obstrução no baço e fígado" que, mesmo com seguidas aplicações de remédios, não se conseguira uma "cura radical, repetindo-lhe vários ataques provenientes pelos vapores dos ácidos minerais que divagavam pela atmosfera do Real Laboratório do salitre. Esses ataques, diz o atestado, colocavam Feijó em "perigo de vida" (Arquivo Histórico da Casa da Moeda. Laboratório de Química, 1810-1826. Arq. 1 - maço 718).

23 Arquivo Histórico da Casa da Moeda. Laboratório de Química, 1810-1826. Arq. 1 - maço 718 .

24 AHU, caixa 17, doc. 984, Fortaleza, 12/5/1803. 
Jardim da Ajuda saíssem daqui vivas, daí sua iniciativa em construir o referido viveiro. ${ }^{25}$

Ao longo de sua permanência no Ceará, Feijó cumpriu seu ofício de naturalista mapeando, descrevendo e explorando objetos de História Natural. Desse trabalho emergem algumas cartas topográficas e um grande número de escritos que vão sendo posteriormente publicados. ${ }^{26}$

Em maio de 1811, João da Silva Feijó foi promovido a Tenente Coronel agregado ao $1 .^{\circ}$ Regimento da Cavalaria de Milícias da Capitania do Ceará e fez uma viagem ao Rio de Janeiro. Por volta de 1818 voltaria ao Rio de Janeiro e, em 1822, já como Tenente Coronel do Corpo de Engenheiros e lente de História Natural, Zoológica e Botânica da Academia Militar, solicitou a José Bonifácio de Andrada e Silva que lhe fossem cedidas salas do Museu Nacional, para serem usadas em suas demonstrações práticas em História Natural, um dia por semana. ${ }^{27}$

25 Arquivo Histórico da Casa da Moeda. Laboratório de Química, 1810-1826. Arq. 1 maço 718 .

26 "Preâmbulo ao ensaio filosófico e político sobre a Capitania do Ceará para servir para a sua história geral". Rio de Janeiro: Imprensa Régia, 1810; “Memória econômica sobre a raça do gado lanígero da Capitania do Ceará, com os meios de organizar os seus rebanhos por princípios rurais, aperfeiçoar a espécie atual das suas ovelhas e conduzir-se ao tratamento delas e das suas lãs em utilidade geral do comércio do Brasil e prosperidade da mesma capitania; escrita e oferecida ao príncipe regente". Rio de Janeiro, 1811. Publicada no Auxiliador da Indústria Nacional, em 1842, e na edição fac-similar de Separatas de artigos da Revista do Instituto do Ceará, tomo 3. Fortaleza: Fundação Waldemar Alcântara, 1997, p. 368-397; "Memória sobre a Capitania do Ceará, 1814". Publicada no Patriota, tomo 3, n. 1, p. 46-62 e na edição fac-similar de Separatas de artigos da Revista do Instituto de Ceará, tomo 3. Fortaleza: Fundação Waldemar Alcântara, 1997, p. 4-27; "Memória sobre as minas de ferro do Cangati do Choró na Capitania do Ceará, escrita em 1814”. Biblioteca Nacional do Rio de Janeiro, Obras raras, 39,5,9; "Memória sobre as antigas lavras de ouro da Mangabeira da Capitania do Ceará", (18-- ?). Publicada na edição fac-similar de Separatas de artigos da Revista do Instituto do Ceará, tomo 3. Fortaleza: Fundação Waldemar Alcântara, 1997, p. 367-370; "Carta topográfica do Ceará à mina Salpetra, descoberta no sítio da Tatujuba na distância de 55 léguas da villa da Fortaleza”, 1800. BNRJ, cartografia, ARC III - 4, 6, 13; "Carta topográfica da Capitania do Ceará para servir à sua história geral", 1809. Autógrafo no Arquivo Militar; "Planta demonstrativa da Capitania do Ceará para servir de plano à sua carta topográfica, delineada pelo sargento mor naturalista, etc"., 1810. Cópia no Arquivo Militar; "Coleção descritiva das plantas da Capitania do Ceará", 1818. In: Estudos sobre a coleção descritiva das plantas do Ceará (com o original inédito do naturalista Feijó). Fortaleza: Gráfica Editorial Cearense, 1984. (Coleção Estudos Cearenses).

27 Museu Nacional do Rio de Janeiro, doc. n. 11, pasta 1. 


\section{O discurso político sobre as minas de ouro do Brasil, $1797^{28}$}

Dentro do conjunto de documentos localizados em diversos arquivos e instituições, o Discurso político sobre as minas de ouro do Brasil ${ }^{29}$ parece ter permanecido em manuscrito. A importância desse documento se relaciona ao fato de se tratar de mais uma obra sobre ouro no Brasil e que, portanto, se insere num vasto conjunto de "Memórias", artigos e discursos escritos naqueles anos de tentativas de recuperação do setor de produção mineral, nomeadamente de ouro. Entre esse conjunto de escritos destaquemos, a título de exemplo, o Discurso sobre o estado atual das minas do Brasil, escrito pelo bispo José Joaquim da Cunha de Azeredo Coutinho. ${ }^{30}$ E o Discurso sobre a verdadeira influência das minas dos metais preciosos na indústria das nações que as possuem, e especialmente da portuguesa, escrito pelo ministro de D. Maria I, D. Rodrigo de Sousa Coutinho. ${ }^{31}$

Ainda nesse período (final do século XVIII e começo do XIX), foram escritas inúmeras "Memórias" sobre o assunto por naturalistas como José Bonifácio de Andrada e Silva (1763-1833) e José Vieira Couto (1752-1827) ${ }^{32}$, além de Feijó, entre muitos outros.

No âmbito desse debate, o texto de Feijó se destaca ao alinhar-se aos defensores da recuperação - pelos métodos racionais - das ativida-

28 O Discurso foi publicado na íntegra na sessão "Fontes" da revista Manguinhos. Cf. SILVA, Clarete Paranhos da Silva; LOPES, Maria Margaret. O ouro sob as Luzes: a "arte" de minerar no discurso do naturalista João da Silva Feijó (1760-1824). História, Ciências, Saúde, Manguinhos, v. 11, n. 3, p. 549-568, set./dez. 2004.

29 Museu Paulista. Manuscritos. Coleção José Bonifácio, D - 79.

30 COUTINHO, José Joaquim de Azeredo. Discurso sobre o estado atual das minas do Brasil. Lisboa: Imprensa Régia, 1804.

31 COUTINHO, Dom Rodrigo de Sousa. Discurso sobre a verdadeira influência das minas dos metais preciosos na indústria das nações que as possuem e especialmente da portuguesa. In: Memórias econômicas da Academia Real das Ciências de Lisboa, para o adiantamento da Agricultura, das Artes, e da Indústria em Portugal, e suas conquistas (1789-1815), tomo I. Lisboa: Banco de Portugal, 1990. p. 179-183.

32 VARELA (2001) estudou as "Memórias" de José Bonifácio de Andrada e Silva. José Vieira Couto foi estudado por C. P. Silva, em dissertação de mestrado defendida em 1999 no Instituto de Geociências da Unicamp e publicada em livro em 2002. Cf. VARELA, Alex Gonçalves. "Juro-lhe pela honra de bom vassalo e bom português": Filósofo Natural e Homem Público - uma análise das memórias Científicas do Ilustrado José Bonifácio de Andrada e Silva (1780-1819). Dissertação (Mestrado) - Instituto de Geociências, Unicamp, Campinas, 2001.; SILVA, Clarete Paranhos da. O desvendar do Grande Livro da Natureza: as práticas geocientíficas no Brasil colonial vistas por meio de um estudo da obra mineralógica e geológica do cientista brasileiro José Vieira Couto, 1798-1805. Dissertação (Mestrado) - Instituto de Geociências, Unicamp, 1999. 
des de mineração, como D. Rodrigo, José Bonifácio e Vieira Couto. Foi escrito no período em que Feijó, tendo retornado de sua viagem a Cabo Verde provavelmente em $1797^{33}$, permaneceu em Lisboa, de onde partiria para o Ceará em 1799. Considerando as análises de Simon $^{34}$ e Brigola ${ }^{35}$, é de se levantar a hipótese de que a redação desse discurso se inseria no processo de capacitação e treinamento naturalista que se desenvolvia em diversas instituições portuguesas, incluindo o Complexo Museológico da Ajuda. Ao mesmo tempo, Feijó, ao redigir o discurso, estaria evidenciando seu conhecimento do estado da arte das discussões sobre o tema e, portanto, suas plenas condições para a continuidade de seu trabalho como naturalista. O que poderia ter contribuído para obter a patente de Sargento-Mor de Milícias da Capitania do Ceará, incumbido de vários objetos de História de Natural.

O Discurso politico sobre as minas de ouro do Brasil é dividido em 3 capítulos subdivididos em pequenos parágrafos (14 ao todo), além de uma parte introdutória na qual Feijó adiantará o que são, para ele, as causas da crise no setor minerador do Brasil, causas estas que receberão tratamento mais detalhado em cada um dos capítulos que compõem o Discurso.

Na parte introdutória de seu Discurso, Feijó afirma ser a mineração, depois da agricultura, a arte mais interessante para a vida do homem, pela utilidade das diversas produções que "a natureza cria e esconde nas entranhas da terra". Feijó escreve que "poucos entre nós estão persuadidos da necessidade de certos e importantes conhecimentos", os quais seriam, em sua opinião, fundamentais para a mineração. Para o naturalista, as causas da crise no setor mineral do Brasil estariam ligadas ao desconhecimento da Mineralogia, da Geometria Subterrânea e da Docimástica, que forneceriam os "princípios fundamentais" para a "arte das minas".

Segundo Feijó, teria sido a abundância e a facilidade de extração de ouro no Brasil que provocaram a falta de uma séria reflexão sobre o

33 Conforme sugere carta de Feijó para Vandelli, escrita de Lisboa em 23 de julho de 1797, mencionada também por GUEDES, Maria Estela; ARRUDA, Luís M. Feijó: naturalista brasileiro em Cabo Verde século XVIII. In: As Ilhas e o Brasil. Portugal/Madeira: Centro de Estudos de História do Atlântico; Secretaria Regional de Turismo e Cultura, 2000, p. 509-523.

34 SIMOM, W. J. Scientific expeditions in the Portuguese overseas territories (1783-1808) and the role of Lisbon in the intellectual-scientific community of the late eighteenth century. Lisboa: CEHCA; Inst. de Investigação Científica Tropical, 1983.

35 BRIGOLA, João Carlos Pires. Coleções, gabinetes e museus em Portugal no século XVIII. Lisboa: Fundação Calouste Gulbenkian; Fundação para a Ciência e Tecnologia, 2003. (Coleção Textos Universitários de Ciências Sociais e Humanas). 
assunto. Por isso, a diminuição da produção seria motivo suficiente para "sérias contemplações políticas na indagação de suas causas".

No Capítulo 1 - "Que a diminuição atual do produto das minas provém da falta dos conhecimentos da Arte das Minas" -, Feijó compara a mineração no Brasil à época dos "primeiros descobrimentos das minas do ouro", com a mineração que se fazia ao tempo em que ele escrevia o Discurso. Nos primeiros tempos, o ouro aparecia à flor da terra e era extraído sem muito trabalho. Atualmente, diz Feijó, as dificuldades de extração do ouro são enormes. Esgotado o ouro de aluvião ou de superfície, acha-se "entranhado pelo centro das montanhas", ou talvez em "diferentes estados de mineralização ou combinação, não sendo reconhecido pelos mineiros que desconhecem todos os princípios fundamentais da arte de trabalhar as minas".

Consoante com o espírito do Século das Luzes, Feijó expressa sua confiança na instrução dos mineiros como uma das mais importantes atitudes a serem tomadas no sentido de superar a crise pela qual passava o setor. Segundo ele, o Brasil se ressentia da falta de professores de "Minas Metalúrgicas e de Docimástica". Daí a ignorância com relação aos "princípios fundamentais" da arte mineira. Essa constatação o leva a concluir que a causa primeira da queda da produção "é sem dúvida, a falta dos precisos conhecimentos por seus operários e diretores".

O Capítulo 2 - "Que a mesma diminuição provém também do uso da circulação do ouro em pó" - é bastante conciso. O objetivo é mostrar que uma situação detectada - a circulação de ouro em pó - deve ser modificada no sentido de se aproveitar ao máximo o potencial econômico do ouro. Na opinião de Feijó, a circulação de ouro em pó acarretaria a perda de quantias nada desprezíveis de ouro e facilitaria "falsificação de mil maneiras praticada pela cobiça", coisas que, conseqüentemente, iam contra o aumento da riqueza nacional. Segundo Feijó, "esta perda resulta um necessário desfalque nos quintos reais e de certa quantidade do trabalho que foi empregado na sua extração".

No Capítulo 3 - "Da necessidade de regular os trabalhos das minas do ouro desde a sua extração até a redução em moeda" -, inspirando-se novamente em regiões de larga tradição em mineração, como Alemanha, Suécia e França, Feijó irá sugerir o que seria, para ele, a maneira mais racional de regular a atividade mineradora. Em sua opinião, a atividade mineradora 
deveria ser regulada "debaixo de vistas mais ativas e inteligentes" para seu melhor aproveitamento.

Feijó defende a presença firme do Estado e de uma legislação que permita racionalizar a produção mineral. Para ele, somente a superfície da terra admite propriedade. Seu interior é direito privativo do Soberano. Daí ser ele o "supremo legislador" desse importante objeto que é a mineração. Citando os regulamentos da França, da Suécia e da Alemanha, o naturalista afirma que seria necessário ter os mesmos cuidados com as minas do Brasil.

Feijó não somente aponta problemas na administração do setor em que as intendências, embora nas mãos de sábios homens e respeitáveis administradores, "mais tendem a formalidades judiciais, que a dirigir, examinar, reparar e ensinar os meios de semelhantes trabalhos para serem verdadeiramente interessantes ao Estado" - como esclarece os meios mais eficazes utilizados por aqueles Estados, em especial a França, para tirar o máximo proveito de suas minas metálicas, entre eles o estabelecimento de aulas públicas nas quais se passavam conhecimentos da arte de trabalhar as minas.

Em relação ao ensino dos conhecimentos necessários a essa área, também a França deveria ser tomada como exemplo. À imitação daquela nação, esse ensino deveria compreender lições de Mineralogia, Química, Docimástica, Física, Geometria Subterrânea e Hidráulica. A França também inspira Feijó em suas sugestões ligadas a uma administração mais "profissional" das regiões mineiras. As intendências deveriam ser formadas de certo número de inspetores, "sujeitos de conhecidas luzes daquele negócio", e que constituiriam "um corpo regular debaixo da previdência do seu respectivo intendente". O intendente mais os inspetores formariam um conselho responsável por discutir, julgar e deliberar sobre todos os assuntos relativos às minas, "para de tudo ser informado exatamente o soberano".

Da mesma forma que em outros textos produzidos no mesmo período, o Discurso caracteriza-se por uma forte retórica das "luzes", pela crítica ao desconhecimento dos "princípios fundamentais" às práticas mineiras e por uma preocupação com a instrução e o treinamento dos mineiros. Como uma "arte", a mineração deveria ser conduzida por "sujeitos de conhecidas luzes" que fossem capazes de colocar em prática seus conhecimentos para a melhor utilização dos recursos da natureza. Nesse sentido, o Discurso aponta 
algumas das questões mais importantes que irão acompanhar as propostas de criação de escolas de mineração no país até o século XIX.

\section{A Memória sobre a Capitania do Ceará}

A Memória sobre a Capitania do Ceará $(1814)^{36}$ é mais um entre os vários textos escritos por Feijó durante suas "diligências filosóficas" na Capitania do Ceará. Tais "diligências" - o termo é utilizado pelo próprio Feijó - constituem a prática de campo das "viagens filosóficas" do final do século XVIII e início do século XIX. A Memória é composta de uma introdução e mais três artigos subdivididos em parágrafos. Os três artigos (e seus respectivos parágrafos) são:

- Artigo 1. Da corografia do Ceará: situação topográfica; limites; extensão da superfície; configuração do terreno; direção da Grande Serra; principais montanhas; sorte de solos, enseadas e portos da costa;

- Artigo 2. Do Físico: do ar em geral; do clima e estações; do verão; causas que moderam seu calor; do inverno; suas chuvas; seu menor calor; umidade da atmosfera e seus efeitos; causa da diferença do calor; e das doenças do país; qualidade física do terreno; sua construção interior e produções do reino mineral; de pedra calcária; raras petrificações; ossada fóssil; terra vegetal; minas de ouro; minas de ferro; minas de cobre; minas de plumbagina; nitreiras naturais; salinas; produções vegetais; das matas; frutificação das árvores e arbustos; hortaliças; produções das plantas indianas; árvores particulares; préstimos de outros vegetais e de suas produções.

- Artigo 3. Do político do Ceará: conclusão; deve-se proteger a arte pastoril; o mesmo da arte piscatória; aproveitamento das salinas; proteção da agricultura em geral; introdução da cultura de muitos vegetais exóticos.

Entre os inúmeros temas observados e discutidos por Feijó, o presente texto se debruçará sobre alguns relacionados ao pensamento mineralógico e geológico de seu tempo. Tais temas aparecem nos artigos $1 \mathrm{e}$ 2 da Memória do naturalista.

36 Ed. fac-similar de Separatas de artigos da Revista do Instituto do Ceará. "Memória sobre a Capitania do Ceará”. Fortaleza: Fundação Waldemar Alcântara, 1997. (Biblioteca Básica Cearense). 


\section{Das regularidades permanentes, montanhas e serras}

Desde o século XVII, as montanhas vinham despertando um grande interesse por parte dos estudiosos da Terra. No século XVIII, o estudo das montanhas e de suas origens se tornou tema obrigatório, aparecendo praticamente em todos os textos que se dedicavam aos estudos da Terra. Fossem resultados de catástrofes que alteraram a crosta terrestre, ruínas do Dilúvio Universal, como defendiam algumas "Teorias da Terra" ${ }^{37}$, ou imponentes exemplos da glória da Criação ${ }^{38}$, elas eram consideradas uma das chaves para a compreensão das origens da crosta e da própria história da Terra.

O "soberbo espetáculo" das montanhas, ou seja, sua altura, suas direções, sua inclinação e sua espessura, entre outras coisas, eram fontes, segundo o naturalista José Vieira Couto ${ }^{39}$, de grandes tumultos e reflexões, e provocavam um desejo de escrutiná-las para descobrir seus recônditos segredos e suas origens. Ao mesmo tempo, como assinala Hazard ${ }^{40}$, o desejo de conhecê-las, em um tempo em que a ciência ainda não havia desenvolvido os meios de possuí-las por completo, causava um sentimento de embaraço, de impotência e, por fim, de irritação.

No século XVIII, as montanhas eram objetos de atenção também pelas suas variadas utilidades. Eram consideradas como os sítios privilegiados para a ocorrência de jazidas metálicas e mineralógicas ${ }^{41}$ e também como

37 A expressão Teoria da Terra é atribuída a uma série de trabalhos que florescem nos séculos XVII e XVIII, e não significa uma teoria específica, mas um "gênero". A partir de um conjunto de condições iniciais (a Terra em fusão, por exemplo) combinado com um conjunto de princípios físicos (as leis de resfriamento dos corpos, por exemplo), construía-se hipoteticamente uma série de eventos que teriam resultado no estado atual da Terra. Cf. RUDWICK Martin. Mineral, Strata and Fossil. In: JARDINE, N., SECORD, J.; SPARY, E. C. (Ed.) Cultures of natural history. Cambridge: Cambridge Un. Press, 1996. p. 267-286.

38 KLONK, Charlotte. Science, Art, and the Representation of the natural World. In: PORTER, Roy (Ed.). The Cambridge History of Science, v. 4. Eighteenth-Century Science. Cambridge: Cambridge University Press, 2003, p. 584-617.

39 MEMÓRIA SOBRE AS MINAS da Capitania de Minas Gerais, suas descrições, ensaios e domicílio próprio à maneira de itinerário; com um apêndice sobre a Nova Lorena Diamantina, sua descrição, suas produções mineralógicas e utilidades que deste país podem resultar, 1801. Revista do Arquivo Público Mineiro, ano 10, p. 55-66, 1905.

40 HAZARD, Paul. O pensamento europeu no século XVIII. Trad. Carlos Grifo Babo. Lisboa: Presença, 1989.

41 GOHAU, Gabriel. História da Geologia. Portugal: Europa-América, 1987. 
parte do ciclo natural da água, sendo que os estudiosos sempre destacavam as muitas fontes e rios que delas vertiam. ${ }^{42}$

Um tal objeto não poderia escapar das anotações de Domingos Vandelli. Sempre preocupado em orientar o trabalho dos filósofos naturalistas e, ao mesmo tempo, mostrando estar atento ao que ocorria no campo da disciplina responsável pelo conhecimento e domínio da natureza - a História Natural -, Vandelli escrevia em sua "Instrução de viagem" de 1779 que o naturalista, ao tratar dos objetos da Mineralogia, deveria principiar pelas montanhas:

[...] que são estas elevações que observamos na superfície da terra. Elas além de conterem os mais ricos tesouros da natureza, são de infinitos outros usos aos homens: as repartições dos Estados, o ar puro, que nelas se respira, o prodigioso número de vegetais que aqui se criam [...] a variedade de fósseis, a formação dos metais, a direção dos ventos, a abundância das águas de que elas são como reservatório; tudo isto faz o mais importante objeto às séries de reflexões de um filósofo. ${ }^{43}$

Como podemos perceber, Vandelli enumera uma série de elementos úteis relacionados às montanhas - ar puro, fósseis, metais preciosos, águas -, o que era uma prática recorrente nos estudos sobre a Terra do período. Nesse campo de investigação, o professor da Universidade de Coimbra nos mostra que a História Natural no Império português, incluindo a América, estava em sintonia com uma prática e uma tradição internacionais e não apenas locais.

Outra característica marcante nos textos de História Natural, dedicados ao campo dos estudos da Terra, e que está explicitamente demarcada nas "Instruções" e nas "Memórias" de caráter mineralógico e geológico do período, refere-se ao que Taylor ${ }^{44}$ chamou de "regularidades permanentes". Segundo esse autor, o estudo das "regularidades permanentes" ou de "disposição"45 constituía-se em prática dominante

42 KLONK, op. cit., p. 584-617.

43 Biblioteca da Academia das Ciências de Lisboa (BAC), Série Vermelha, ms. 405. "Viagens Filosóficas ou Dissertação sobre as importantes regras que o Filósofo Naturalista nas suas peregrinações deve principalmente observar", por D.V., 1779, p. 17-18.

44 TAYLOR, Kenneth L. Les Lois Naturelles dans la Géologie du XVIIIème siècle: Recherches Préliminaires. Travaux du Comité Français d'histoire de la Géologie, 3. ${ }^{a}$ série, t. 2, n. 1, 1988.

45 Além da expressão regularidades permanentes, Taylor usa também regularidades estáticas, condições constantes e regularidades de disposição como sinônimas. 
nos estudos "geológicos" 46 do século XVIII. Nesses estudos, a preocupação em descrever certas características da crosta terrestre prevalecia em relação à preocupação de se buscar os processos que teriam dado origem a essas características.

Ao analisar os escritos de diversos naturalistas ${ }^{47}$ que se dedicaram aos estudos da Terra, o autor acima citado identifica as regularidades que mais aparecem. São elas: os grandes traços dos continentes; a posição dos maciços continentais e dos oceanos; as medidas e orientações do globo; a localização e a profundidade dos rios, a direção das águas dos rios e dos mares, a disposição das camadas estratigráficas, a relação entre as camadas estratigráficas e os minerais nelas contidos, a correspondência dos ângulos das montanhas paralelas; a altura e a direção das montanhas, a direção de seus veios, etc.

Seguindo essa tradição, e ainda sobre as montanhas, a "Instrução" do professor Vandelli ${ }^{48}$ recomenda que sejam observadas as suas ordens, ou seja, se são primárias, secundárias ou terciárias ${ }^{49}$, e certas regularidades, como o arranjo de suas camadas, a disposição de seus veios, de que tipo de "pedras" ou "terras" era formado. Observar a correspondência dos ângulos das montanhas paralelas poderia, segundo observa o professor, "dar muita luz à História Natural sobre a Teoria da Terra".

Muito provavelmente o professor Vandelli acompanhava, como muitos outros no mesmo período, as idéias do influente Buffon..$^{50} \mathrm{O}$ princípio da correspondência dos ângulos era, segundo Taylor ${ }^{51}$, uma das regularidades mais discutidas pelos "geólogos" do XVIII. Por esse princípio, quando

46 De maneira genérica, até o início do século XIX, aqueles que se dedicavam aos estudos sobre a Terra chamavam a si mesmos de mineralogistas. O termo geologia, no sentido de expressar os conhecimentos sobre o globo terrestre, já fora proposto desde 1778 por Jean André De Luc (1727-1817), mas só passou a ser utilizado largamente no início do século XIX.

47 Entre eles Buffon (1707-1788), Louis Bourguet (1678-1742), Nicolas Demarest (1725-1815), Horace Bénédict de Saussure (1740-1799) e Jean André De Luc (1727-1817).

48 Biblioteca da Academia das Ciências de Lisboa (BAC), Série Vermelha, ms. 405. "Viagens Filosóficas ou Dissertação sobre as importantes regras que o Filósofo Naturalista nas suas peregrinações deve principalmente observar", por D.V., 1779.

49 Nesse período, não havendo meios de datar com precisão, esses termos eram utilizados para atribuir uma idade relativa às montanhas, sendo as primárias as mais antigas e as terciárias as mais novas.

50 Cf. BELTRÁN MARÍ, Antônio. Introdução e notas. In: BUFFON, G-L. Las epocas de la naturaleza, 1779. Madri: Alianza, 1997.

51 TAYLOR, op. cit. 
duas montanhas estivessem paralelas, os ângulos dos dois lados deveriam ser correspondentes.

Buffon $^{52}$, que confere à água um papel importante na formação das montanhas e da crosta terrestre em geral, escrevia que "el agua es la única que, como causa general y subsecuente a la del fuego primitivo, acabó construyendo y configurando la superficie actual de la Tierra". E mais adiante continua: "las montañas compuestas de piedras calizas fueron construidas sin duda en este mar antiguo, cuyas diferentes corrientes, es igualmente indudable, las esculpieron con ángulos que se corresponden". Pelo raciocínio de Buffon, ângulos paralelos eram sinal da formação da atual crosta sob as águas.

Em suas observações, João da Silva Feijó coloca-se dentro de uma tradição vigente no seu tempo quando trata das montanhas, assim como de suas regularidades externas. Isso fica evidente pelos títulos que Feijó confere aos parágrafos 5. e $6 .^{\circ}$ respectivamente: "Direção da Serra Grande" e "Principais montanhas". Nesses dois curtos parágrafos, Feijó dá ênfase à descrição das montanhas e seus arredores, descrevendo algumas de suas regularidades. Sobre a Serra Grande, o autor aponta onde começa e para onde se dirige outra questão que inquietava os estudiosos da Terra do período. Como dizia Vandelli em sua "Instrução" de 1779, os naturalistas deveriam observar a direção das montanhas que "na América costuma ser toda diferente estendendo-se os montes mais do norte ao sul do que do oriente ao ocidente". ${ }^{53}$

Sobre as principais montanhas, além de apontar quais são, Feijó faz comentários sobre as planícies, os rios e as lagoas que fazem parte da paisagem próxima aos terrenos montanhosos, o que nos remete mais uma vez à "Instrução" de Vandelli, na qual ele diz que "estas observações, que supomos fazerem-se nos montes, devem se fazer nos seus vales, colinas, planícies, rochedos, rios, e em uma palavra em toda a terra geralmente, ainda que nela não haja suspeita de minas" ${ }^{54}$.

52 Cf. BELTRÁN MARÍ, op. cit, p. 254.

53 Biblioteca da Academia das Ciências de Lisboa (BAC), Série Vermelha, ms. 405. "Viagens Filosóficas ou Dissertação sobre as importantes regras que o Filósofo Naturalista nas suas peregrinações deve principalmente observar", por D.V., 1779.

54 Ibid., p. 25. 


\section{Fósseis: evidências contra Buffon e outros detratores da América}

Nos parágrafos 25 e 26, denominados respectivamente "Raras petrificações" e "Ossada fóssil", Feijó faz observações sobre características paleontológicas da região. Tais observações não somente mostram suas idéias sobre os fósseis, mas também o colocam dentro da disputa sobre a alegada inferioridade da América, questão que se apresentava aos naturalistas desde a segunda metade do setecentos, a partir dos escritos de um dos mais importantes naturalistas do século XVIII, e já anteriormente referenciado, George-Louis Leclerc, Conde de Buffon. Em obra publicada entre 1749 e $1804,{ }^{55} \mathrm{o}$ eminente naturalista apresentou algumas idéias sobre o continente americano que iniciaram essa disputa. No que concerne aos aspectos geológicos, o Novo Mundo seria, segundo Buffon, muito mais novo se comparado ao velho continente, pois apresentava sinais de que emergira das águas posteriormente. Em um ambiente dominado por uma grande quantidade de rios, lagos e pântanos, além de um clima quente e úmido e uma vegetação que impedia a penetração dos raios solares, a América só poderia sustentar uma natureza viva inferior. Daí a América possuir uma enorme quantidade de insetos e répteis. Quanto ao homem do continente, ele seria de menor estatura e mais fraco e, por isso mesmo, impossibilitado de dominar a natureza. ${ }^{56}$

As idéias de Buffon, seguidas por outros intelectuais e naturalistas europeus, deram origem a uma intensa polêmica. No Brasil, essa questão ainda estava na ordem do dia na segunda metade do século XIX, como se pode apreender do artigo de Lorelai Kury ${ }^{57}$, tratando do trabalho do médico e naturalista Silva Maia. Segundo a autora, Silva Maia "reconhece ser verdadeira a opinião de Buffon de que os animais do Novo Mundo seriam menores do que os do velho continente". No entanto, e invertendo o jul-

55 BUFFON, Georges-Louis Leclerc. Histoire naturelle, générale et particuliére, avec de la description du Cabinet du Roi. Paris, 1749-1804. 44 v.

56 Para um aprofundamento sobre essa questão, veja-se: FONSECA, Maria Rachel de G. Fróes. A única ciência é a Pátria: o discurso científico na construção do Brasil e do México (1770-1815). Tese (Doutorado) - Universidade de São Paulo, São Paulo, 1996; GERBI, Antonello. O Novo Mundo: história de uma polêmica (1750-1900). Trad. Bernardo Joffily. São Paulo: Companhia das Letras, 1996.

57 KURY, Lorelai. Ciência e Nação: romantismo e história natural na obra de E. J. da Silva Maia. História, Ciências, Saúde, Rio de Janeiro, v. 2, p. 267-291, jul./out. 1998. 
gamento de Buffon, apresenta a América meridional como possuidora de quantidade e variedade de animais superior às da Europa. Exatamente ao contrário do que afirmara Buffon, Silva Maia acha que o calor e a umidade eram favoráveis ao desenvolvimento da vida.

Mas como Feijó se coloca dentro dessa controvérsia?

Sobre as "raras petrificações", o naturalista afirma:

Notam-se na serra dos Cariris, onde se diz Milagres, 80 léguas para mais, longe do mar e naquela elevação, as mais raras e curiosas petrificações vagas de peixes e de muitos gêneros de anfíbios, e alguns de grandeza de 4 palmos, incluídos como em uma espécie de Etites, de substância calcária, em cujo âmago se observa o animal totalmente perfeito e reduzido interiormente a uma cristalização espatosa. ${ }^{58}$

Sobre as ossadas fósseis, de "grandioso tamanho, como vértebras, costelas e fêmures", que Feijó encontrará em um local denominado Lagoa Catharina, ele observa:

Que exemplos pois para suas provas não deduzirão destes objetos os sectários do célebre sistema de Buffon? Não menos para aqueles naturalistas que se persuadem que não podem petrificar as substâncias moles ou carnosas dos animais. ${ }^{59}$

As duas citações mostram em primeiro lugar que Feijó se opunha a uma idéia ainda em voga entre muitos naturalistas da época para os quais as partes "moles ou carnosas" dos animais não poderiam se "petrificar". ${ }^{60}$ Em segundo lugar, vemos que Feijó se coloca frontalmente contra Buffon ao enfatizar a grandeza das ossadas encontradas. A maneira como ele constrói seu discurso mostra mesmo uma dose de ironia em relação às posições buffonianas. Como os sectários seguidores de Buffon, que afirmavam ser a natureza viva da América inferior, que seu ambiente produzia seres pequenos e frágeis, explicariam a grandeza das ossadas encontradas?

58 Ed. fac-similar de Separatas de artigos da Revista do Instituto do Ceará. "Memória sobre a Capitania do Ceará"; Fortaleza: Fundação Waldemar Alcântara, 1997 (Biblioteca Básica Cearense), p. 13.

59 Ibid., p. 13.

60 PINHEIRO, Rachel; LOPES, Maria Margaret. João da Silva Feijó (1760-1824) no Ceará: um elo entre a ilustração brasileira e a construção local das ciências. Atas do $1 .{ }^{\circ}$ Congresso Luso-Brasileiro de História das Ciências e da Técnica (2000). Universidades de Évora e Aveiro, Portugal, 2002. 


\section{Considerações finais}

Acredito que as investigações que tenho realizado sobre Feijó têm contribuído para o resgate da trajetória do naturalista no Ceará, no que diz respeito às suas observações nos campos da mineração, da Mineralogia e da Geologia do período em questão. Porém, é justo dizer que, ainda na segunda metade do século XIX, importantes figuras do meio científico do Império ligadas ao Instituto Histórico e Geográfico Brasileiro e à Sociedade Vellosiana - como o médico e naturalista Emílio Joaquim da Silva Maia (1808-1859) e o também médico e naturalista Francisco Freire Allemão (1823-1874) - já haviam tentado resgatar a obra de Feijó.

A Comissão Científica de Exploração (1859-1861) ${ }^{61}$, formada somente por naturalistas nacionais - pois se inseria nos projetos de construção do Estado Imperial e da nação ${ }^{62}$-, teve seus trabalhos centrados na província do Ceará. Segundo Rachel Pinheiro: “Ao mesmo tempo em que estes naturalistas buscaram firmar uma ciência nacional, praticada por nacionais e definindo a identidade nacional, eles realizaram resgates da História Natural do final do século XVIII, e muitos destes resgates influenciaram diretamente nas atividades da Comissão". ${ }^{63}$

É o caso, por exemplo, de Feijó, que teria exercido influência sobre a Comissão pelo seu profundo conhecimento do Ceará. Alguns integrantes da Comissão, como o já citado Freire Allemão, diretor da Seção de Botânica, e Guilherme Schüch de Capanema (1824-1908), diretor da Seção Geológica e Mineralógica, já conheciam o trabalho do naturalista. Freire Allemão, juntamente com Silva Maia, havia recuperado e organizado alguns manuscritos de Feijó, usados como guia para os trabalhos da Seção Botânica da Comissão. Os trabalhos mineralógicos de Feijó também seriam

61 Sobre a Comissão e suas ligações com Feijó, me baseio em PINHEIRO, Rachel. As histórias da Comissão Científica de Exploração (1856) na correspondência de Guilherme Schüch de Capanema. Dissertação (Mestrado) - Instituto de Geociências, Unicamp, Campinas, 2002.

62 Sobre o papel da ciência e de instituições científicas como o IHGB e o Museu Nacional na construção da nação, ver, entre outros, DANTES, Maria Amélia. Fases da implantação da ciência no Brasil. Quipu, v. 5, n. 2, maio/ago. 1988, p. 265-275; FIGUEIRÔA, Silvia Fernanda de Mendonça. As ciências geológicas no Brasil: uma história social e institucional, 1875-1934. São Paulo: Hucitec, 1997; LOPES, Maria Margaret. O Brasil descobre a pesquisa científica: os museus e as ciências naturais no século XIX. São Paulo: Hucitec, 1997; KURY, op. cit., 1998, p. 267-291. Sobre o IHGB, ver também GUIMARÃES, Lúcia. O Império de Santa Cruz: a gênese da memória nacional. In: HEIZER, Alda; PASSOS, Antonio Augusto (Org.). Ciência, civilização e Império nos trópicos. Rio de Janeiro: Access, 2001. p. 265-285.

63 PINHEIRO, op. cit., p. 36. 
validados ou refutados por Capanema, que escreveu em seu relatório da Seção Geológica e Mineralógica: "Fizemos uma excursão ao Canindé, e fomos ver os depósitos de ferro junto a serra dos Guaribas nas margens do rio Cangatí, de que falara Feijó em 1814; encontramos realmente esta rica mineira, de todo desprezada." ${ }^{4}$

Como se pode perceber, os conhecimentos por Feijó produzidos foram referências para as investigações em ciências naturais passados quase 40 anos de sua morte.

Os dados reunidos por Feijó também foram utilizados por Thomas Pompeu de Sousa Brasil, figura de prestígio nos meios científicos, políticos e sociais cearenses da segunda metade do século XIX. Um cotejamento entre a Memória sobre a Capitania do Ceará (1814), de Feijó, e o ensaio estatístico da Província do Ceará ${ }^{65}$, de Brasil, nos revela diversos exemplos. ${ }^{66}$

Diante do exposto, o que se pode concluir é que se as iniciativas com o sentido de resgatar práticas científicas do final do período colonial, entre elas as de Feijó, não surtiram o efeito desejado, isto é, recuperar e guardar na memória e na história uma tradição científica local, é porque essas mesmas iniciativas foram, por sua vez, também relegadas à obscuridade e apenas recentemente vêm sendo reveladas pela historiografia.

64 Citado em PINHEIRO, op. cit., p. 41.

65 BRASIL, Thomaz Pompeu de Sousa. Ensaio Estatístico da Província do Ceará. 2 tomos. Ed. Fac.sim. (1864). Fortaleza: Fundação Waldemar Alcântara, 1997 (Coleção Biblioteca Básica Cearense).

66 Veja-se, por exemplo, Capítulo 2 do título I da primeira parte, intitulado "Dimensões" (p. 7), onde Brasil calcula a dimensão da capitania confrontando seus números com os de Feijó; Capítulo 4, título I, intitulado "Aspecto físico" (p. 9); Capítulo 10, "Constituição geológica”, do título I, primeira parte, onde Brasil observa em nota de rodapé que "aos Drs. Capanema, Feijó (antigo naturalista) e Theberge devo as informações sobre esse artigo". Ainda no Capítulo 10, quando trata do tema "Fenômenos vulcânicos", Brasil utiliza-se de Feijó e de Capanema; Capítulo 1, do título IV, primeira parte, quando trata do "Reino mineral (Mineralogia)", Brasil escreve em nota de rodapé: servem-me de guia neste estudo as Memórias do naturalista Feijó, as informações dos Drs. Capanema e Theberge, boticário Mamede e outros (p.145). Cf. BRASIL, Thomaz Pompeu de Sousa. Ensaio estatístico da Província do Ceará. 2 tomos. Ed. fac-similar. (1864). Fortaleza: Fundação Waldemar Alcântara, 1997. (Coleção Biblioteca Básica Cearense). 